\title{
SEMI-FINISHED MATERIAL AND SEMI-SOLID FORGING OF SIC PARTICLE REINFORCED AL-MG LIGHT METAL MATRIX COMPOSITES - NEW RESULTS ON PROCESS DEVELOPMENT AND CHARACTERISATION
}

\author{
Martin Wenzelburger ${ }^{1 *}$, Selahattin Babat ${ }^{1}$, Helen V. Atkinson ${ }^{2}$, and Rainer Gadow ${ }^{1}$ \\ ${ }^{1}$ Universität Stuttgart, IFKB (Institut für Fertigungstechnologie keramischer Bauteile / \\ Institute for Manufacturing Technologies of Ceramic Components and Composites) \\ ${ }^{2}$ University of Leicester, Department of Engineering, Mechanics of Materials Research Group
}

\begin{abstract}
Particle reinforced light metal matrix composites (MMC) were manufactured by thermal spraying of semi-finished material (atomisation and co-deposition of reinforcement particles and metal melt), followed by inductive reheating and semi-solid forging. The matrix alloy was $\mathrm{Al} \mathrm{Mg3}$, silicon carbide was used as particulate reinforcement. Semi-finished material processing was optimised regarding particle size and temperature distribution during material deposition in order to obtain a suitable microstructure for subsequent semi solid processing. Twin wire electric arc spraying with cored wires was applied, providing the matrix and reinforcement materials at the same time for simultaneous deposition. Process analysis was made by in-flight particle diagnostics. Semi-solid processing ability of the MMC material after thermal spraying was verified by manual deformation testing. Inductive reheating of the particle reinforced material was coupled with fast semi-solid forging by an axial press into a closed, plate-shaped die. Optical and Scanning Electron Microscopy showed some inhomogeneity in the SiC particle distribution. However, mechanical properties from tensile and 4-point bending experiments were encouraging.
\end{abstract}

KEYWORDS: Composite Material, Metal Matrix Composite, Aluminium-Magnesium Alloy, Particulate Reinforcement, Silicon Carbide, Thermal Spraying, Twin-Wire Electric Arc, Semi-Solid Processing, Thixoforging.

\section{INTRODUCTION}

This paper describes recent advances and developments in the processing of particle reinforced metal matrix composites (MMC) by thermal spraying of semi-finished material (billets) and forming in the semi-solid state. This method was developed to gain distinct advantages in comparison to conventional processing of particle reinforced metals (PRM), especially aluminium alloys:

- high process flexibility (materials, shape and dimensions of semi-finished parts, microstructure),

- high forming ability, complex component shapes,

- fine microstructure,

- low chemical reaction with reinforcement materials,

- low porosity, and

- low process cycle times.

Conventional processes are, e. g., mixing of particles into a melt and subsequent casting, infiltration of particle preforms, spray deposition (spray forming), in-situ processes and powder metallurgical processes [1]. As an alternative to spray forming, different spray techniques were applied for composite processing [2]. First work on thermal spray (TS) deposition of $\mathrm{Al} \mathrm{Si6}$ on carbon fibre reinforcements for subsequent thixoforming showed the suitability of TS aluminium alloys for processing in the semi-solid state and the possibility of MMC manufacturing via this two-step route [3, 4]. Furthermore, thermally sprayed billets were manufactured of $\mathrm{Al}$ and AA 2017 (Al Cu4MgSi) alloy with alumina and silicon carbide particle reinforcements in previous work [5]. Thereby, twin-wire electric arc spraying was used with cored wires, consisting of the matrix material as the wire mantle and the ceramic reinforcement particles as the wire powder filling.

The present work continues thermal spray process optimisation by means of in-flight spray particle and microstructure analysis. PRM billets were produced and thixoforging experiments with parameter variations were carried out in order to investigate formability and final product properties of the resulting MMC components.

\section{SEMI-FINISHED MMC MATERIAL}

The material applied in this work was a cored wire of $2.15 \mathrm{~mm}$ in diameter from Welding Alloys France SAS, Holtzwihr, France. The mantle material was AA 5754 (EN AW-5754 [Al Mg3]), which was chosen as a sample material due to its good formability that enabled easy

\footnotetext{
* Corresponding author: Universität Stuttgart, IFKB, Allmandring 7b, Stuttgart, D-70569, Germany Phone: +49(0)711/685-68228; Fax: +49(0)711/685-68299; E-mail: martin.wenzelburger@ifkb.uni-stuttgart.de
} 
processing as cored wires. The powder filling was agglomerated silicon carbide. The $\mathrm{SiC}$ content in the wires was $26.2 \%$ vol., with a primary grain size of $\mathrm{D}_{50}=$ $20 \mu \mathrm{m}$ and size of the agglomerates of $\mathrm{D}_{50}=173 \mu \mathrm{m}$ $\left(\mathrm{D}_{90}=536 \mu \mathrm{m}\right)$.

\subsection{BILLET DEPOSITION BY THERMAL SPRAYING - PROCESS OPTIMISATION}

For the billet deposition analysis described here, a Sparc 400 arc wire spraying facility from GTV $\mathrm{mbH}$, Luckenbach, Germany, was applied, using compressed air for melt atomisation. The substrate was a copper plate on a rotating table with a compressed air cooling from the bottom [5]. The torch was moved vertically in discrete steps of some millimetres during billet build-up. The cylindrical billet shape was optimised by variation of the holding times at each position. Limitation of the torch path on a linear movement enabled the optimization of the process towards billet shape and process reproducibility, and thus, automation of the billet processing.

For analysis of the influence of thermal spray parameters on the semi-finished material microstructure, parameter variation experiments were made, see Table 1. Deposition angle, torch distance and substrate rotational speed were constant during all experiments. The wire feed rate was constant at $\mathrm{f}=4 \mathrm{~m} / \mathrm{min}$. As standard parameters, $\mathrm{E}=27.5 \mathrm{~V}$ voltage and $\mathrm{p}=4$ bar atomisation gas pressure were identified, leading to the best stability of the thermal spray process with this setup.

\section{Table 1: Parameter variations during billet deposition}

\begin{tabular}{lrr}
\hline $\begin{array}{l}\text { TS parameter set } \\
\text { no. }\end{array}$ & $\begin{array}{r}\text { Voltage, E } \\
(\mathrm{V})\end{array}$ & $\begin{array}{r}\text { Atomisation gas } \\
\text { pressure, p (bar) }\end{array}$ \\
\hline TS-1 (lower E) & 22.0 & 4 \\
TS-2 (standard) & 27.5 & 4 \\
TS-3 (higher E) & 36.0 & 4 \\
TS-4 (higher p) & 27.5 & 6 \\
\hline
\end{tabular}

Requirements for the semi-finished material prior to semi-solid processing are:

- a globular microstructure, and

- two distinct phases of different melting temperature intervals.

Generally, thermal spraying can lead to a fine-grained microstructure that is suitable for thixoforming [3, 4]. However, the microstructure of TS deposits depends on the direct process parameters, i. e. temperature, size and velocity of the spray particles (droplets and solid particles in the spray jet) prior to deposition on the substrate. In turn, these can be influenced by the indirect process parameters, or parameters of the arc wire installation, see Table 1 (further secondary parameters are, e. g.: wire feed rate, torch distance etc.). In order to optimise the material for semi-solid processing, the correlations between direct and indirect process parameters have to be analysed.

Spray particle parameters were analysed by in-flight particle measurement with the SprayWatch ${ }^{\circledR}-3 i$ High Resolution system from Oseir Ltd., Tampere, Finland
[6]. This resulted in the spray particles' temperatures, velocities and relative flux (number of particles in the measurement volume, which is a reciprocal measure of the average particle size). The results for temperature and flux for different TS parameters at a distance of 75 $\mathrm{mm}$ from the torch exit (similar to the spray distance) are displayed in Figure 1.

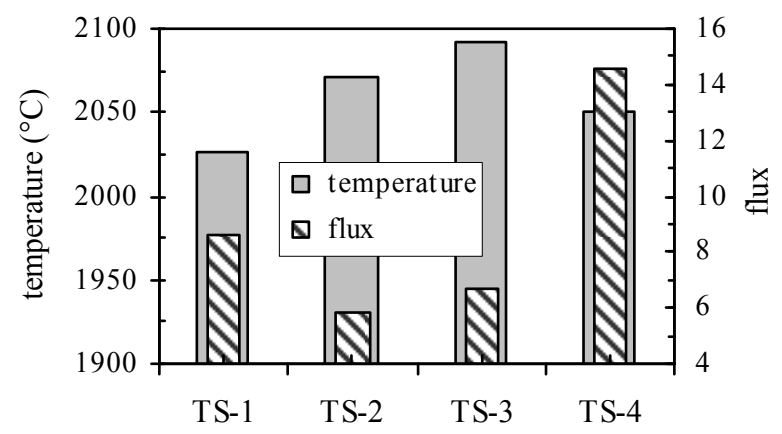

Figure 1: Particle properties for different TS parameters

Temperature results yield a clear dependency of the spray particle temperature from the arc voltage. The temperature correlation with the atomisation gas pressure is very weak. More gas flux leads to stronger cooling of the particles, but at the same time, the velocity increases, leading to shorter dwell (and cooling) time in the spray. The spray particle sizes increase with increasing voltage, but decrease strongly with increasing atomisation gas pressure. As a consequence, it has to be argued that in order to achieve a fine-grained matrix structure and limit billet temperature during the deposition process, the TS voltage should be as low as possible and the atomisation gas pressure should be high. Nevertheless, arc stability also depends on these process parameters, and thus, parameter variations are only possible within a limited range (as given in Table 1).

\subsection{MICROSTRUCTURE OF AS-SPRAYED, SEMI-FINISHED MATERIAL}

The microstructure of the as-sprayed PRM materials was analysed by light microscopy and SEM. The globular grains in the AA 5754 alloy were in the range of $1 \mu \mathrm{m}$ in size, without large variation for different TS parameters. However, the spray parameters had an influence on the spray particle size, and thus, on the billet porosity. For larger arc voltage, the splats are larger, leading to higher surface roughness during deposition and higher porosity. In Figure 2, the microstructure is shown for standard parameters (TS-2) and lower voltage (TS-1). The TS-2 sample shows larger splats with more splat deformation, while sample TS-1 has a finer structure with layered, aligned splats. The porosity was in the region of $2.8 \%$ for TS-2 and $1.8 \%$ for TS-1. For higher pressure (TS- 4 ), the porosity was in the region of $1.6 \%$, because the spray particles were smaller with higher velocity at the same time, leading to increased deposit compaction.

During cored wire spraying, a large fraction of the $\mathrm{SiC}$ agglomerates was fragmented, leading to good dispersion of single particles in the matrix. However, 
numerous agglomerates were embedded into the matrix, see e. g. Figure 3, leading to an increase in porosity of 0.5-2.5\%, depending on the TS parameters and the position in the billets (porosity values given above are including the pores in these agglomerates). Overall differences in porosity and agglomerates were small between the different sets of TS parameters.
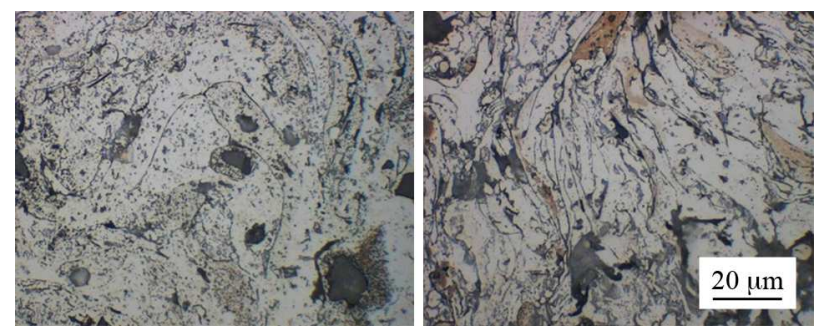

Figure 2: SEM, AA 5754-SiC material as-sprayed, parameters TS-2 (standard; left) and TS-1 (right)

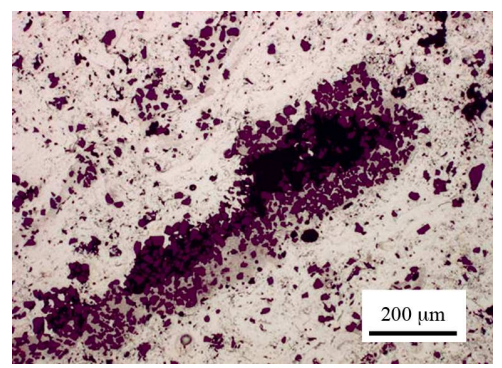

Figure 3: Micrograph, AA 5754-SiC material as-sprayed, particle distribution with preserved agglomerate

\section{SEMI-SOLID MMC PROCESSING}

The formability of the as-sprayed PRM was tested by heating in a convection kiln to $620{ }^{\circ} \mathrm{C}$ and manual deformation with a spatula, see Figure 4 . At $620^{\circ} \mathrm{C}$, the matrix material has a liquid content of $47.6 \%$ vol., which was measured by DTA. For further processing, the billets were machined to nominal diameter, removing the surface area with increased porosity.

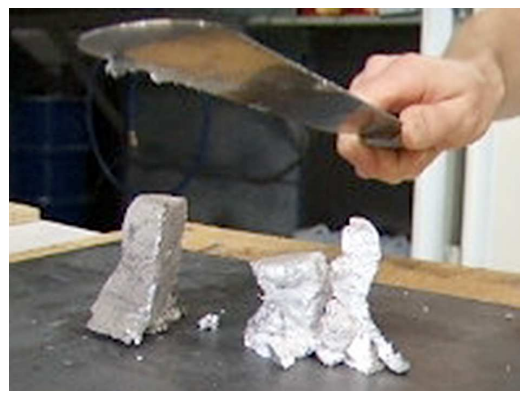

Figure 4: Thixoforming test with thermal spray billet

\subsection{THIXOFORGING PROCESS}

The thixoforging installation consisted of an inductive reheating unit, a hydraulic axial press, and a plate-shaped steel die. The die temperature was $300{ }^{\circ} \mathrm{C}$ during all experiments.

During semi-solid processing, different heating and forging parameters were applied. Thereby, the reheating temperature was measured and controlled by means of thermocouples, while the forging parameters (pressure and punch speed) were pre-defined. The temperature of the material prior to thixoforging was varied in-between $580-630{ }^{\circ} \mathrm{C}$ to find a suitable forming temperature. The press force was varied in-between $10-40 \mathrm{kN}$. However, results presented in the following are only for different press forces, because thixoforging results were insufficient for temperatures below $630^{\circ} \mathrm{C}$.

\subsection{MICROSTRUCTURE OF FINAL MMC}

In Figure 5, densification results are presented for semifinished materials with different TS parameters (TS-1, TS-2, and TS-4) that were thixoforged at $630{ }^{\circ} \mathrm{C}$ with a press force of $20 \mathrm{kN}$. The samples show a different residual porosity, which is the highest for standard parameters (TS-2), lower for reduced voltage (and thus, smaller spray particles; TS-1), but the lowest for higher atomization gas pressure (TS-4), which led to reduced porosity already in the semi-finished material. However, residual porosity in the final MMC can be controlled by the thixoforging parameters (at the cost of increased tool loading and wear). Therefore, the microstructure prior to thixoforging is more important than porosity.

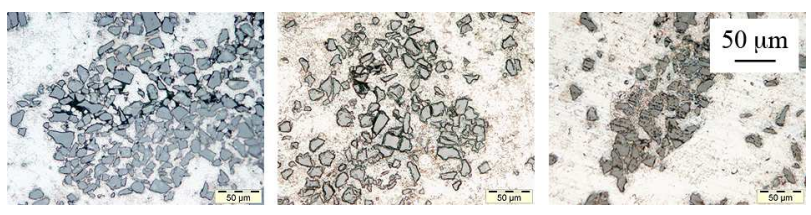

Figure 5: Micrographs, thixoforged AA 5754-SiC MMC $(20 \mathrm{kN})$; left to right: TS-2, TS-1, and TS-4 billets

Thixoforging samples (billet parameters TS-2) with variation of the press force $(10 \mathrm{kN}$ and $40 \mathrm{kN})$ are shown in Figure 6. Thereby, the $10 \mathrm{kN}$ sample shows some residual porosity and particle agglomerates are not well infiltrated with matrix alloy. In contrast, the sample with $40 \mathrm{kN}$ is completely dense and shows a more homogeneous particle distribution, because agglomerates were infiltrated or destroyed during densification.

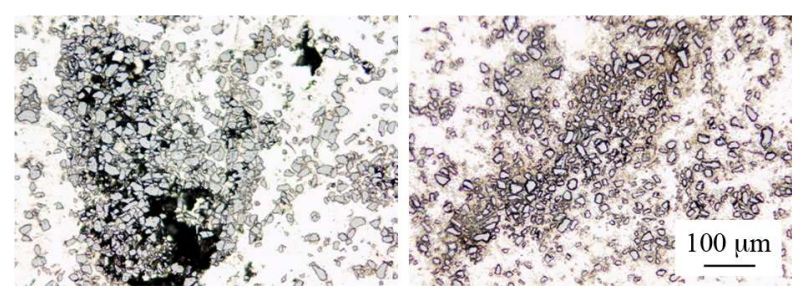

Figure 6: Micrographs, AA 5754-SiC MMC, thixoforged with $10 \mathrm{kN}$ (left) and $40 \mathrm{kN}$ (right) press force

EDX analysis yielded the presence of silicon-rich phases in the matrix after thermal spraying and thixoforging. This can be attributed to reactions of liquid melt with $\mathrm{SiC}$ particles [7], which may be applied for in-situ alloying during thermal spraying. However, the distribution of silicon-rich phases in the matrix alloy is inhomogeneous and this would have to be improved by further work on process control. 


\subsection{MECHANICAL PROPERTIES}

The strength of the resulting AA 5754-SiC MMC was measured for different press forces during the thixoforging process $(10,17,20$ and $40 \mathrm{kN})$. Thereby, tensile experiments and 4-point bending experiments were made according to [8] and [9], respectively. Tensile experiments were made on a MTS 810 Material Test System, while bending experiments were made on a Zwick Z100 testing machine. Figure 7 shows the results for UTS and bending strength as well as stiffness.

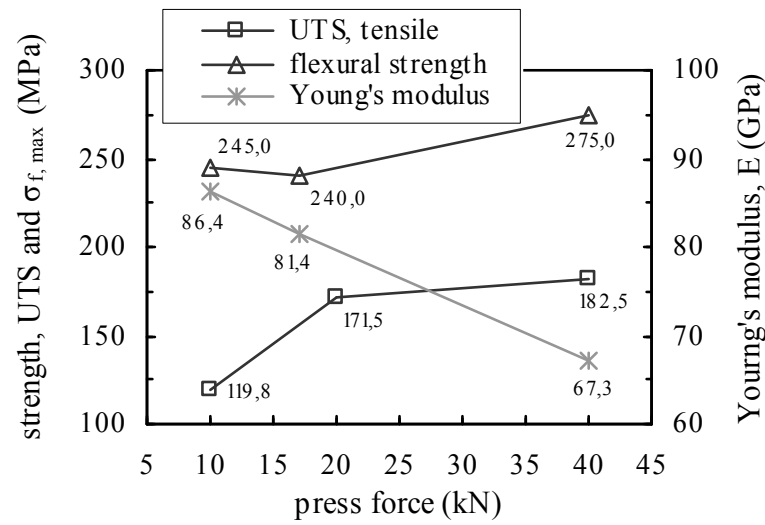

Figure 7: Tensile and 4-point bending results, AA 5754SiC thixoforged; variation of press forces (10-40 kN)

The materials' properties show a dependency from densification press force during thixoforging, which may be attributed to the residual porosity in case of press forces lower than $40 \mathrm{kN}$. However, results from tensile and 4-point bending experiments are not completely consistent, because of the decrease in flexural strength for $17 \mathrm{kN}$. Moreover, results for the Young's modulus, which was derived from bending experiments, show a linear decrease for increasing densification force. Especially the Young's modulus at $40 \mathrm{kN}$ is lower than for non-reinforced AA 5754 material, which is $\mathrm{E}=70$ $\mathrm{GPa}$. The tensile strength of the non-reinforced material is $190-240 \mathrm{MPa}$.

\section{SUMMARY AND CONCLUSIONS}

A method for manufacturing of particle reinforced light metal alloy MMC with aluminium matrix and ceramic reinforcement was presented, which involves thermal spraying with cored wires for manufacturing of semifinished material and thixoforging for densification and forming of MMC components. Thereby, twin wire electric arc spraying results in a fine-grained, globular like structure that enables further processing in the semisolid state. Thixoforging for matrix densification leads to a dense final MMC material, depending on the press force during forging. The mechanical properties of the produced AA 5754-SiC samples were tested with encouraging results. However, segregation effects and chemical reaction of the matrix alloy with the particles in the case of silicon carbide may occur, and particle distribution in the matrix is inhomogeneous due to the application of agglomerated powders during spraying.
Further work should be done on optimisation of the assprayed microstructure. Furthermore, a study on the possibilities in component geometry (complexity) that is accessible by thixoforging would also be valuable.

\section{ACKNOWLEDGEMENTS}

The contribution of student assistant Ms. Bianca Preuth in Stuttgart on experimental thermal spray analysis and the continuous experimental support of the academic and technical staff in Leicester is gratefully acknowledged.

\section{REFERENCES}

[1] D. J. Lloyd. Particle reinforced aluminium and magnesium matrix composites. Int. Mater. Rev. 39(1):1-21, 1994.

[2] T. S. Srivatsan, E. J. Lavernia. Review - Use of spray techniques to synthesize particulate-reinforced metal-matrix composites. J. Mat. Sci. 27 (1992) 5965-5981.

[3] K. Siegert, R. Gadow, K. v. Niessen, P. Unseld, and M. Speicher. Thixoforging of continuous fiber reinforced AlSi / AlMg- alloys. In: Proc. $8^{\text {th }}$ Int. Conf. on Semi-Solid Processing of Alloys and Composites, S2P 2004, Limassol, Cyprus, September 21-23, 2004, Paper \# 23-3. Wheeling, IL, USA : NADCA, 2004.

[4] K. v. Niessen, M. Wenzelburger, and R. Gadow. Prepreg manufacturing by thermal spraying for thixoforming of light metal MMCs. In: Proc. $9^{\text {th }}$ Int. Esaform Conf. on Material Forming, ESAFORM 2006, pp. 830-834. Glasgow, United Kingdom, April 26-28, 2006.

[5] M. Wenzelburger, C. Zimmermann, and R. Gadow. Advances in Thermal Spray Deposition of Billets for Particle Reinforced Light Metals. In: AIP Conference Proceedings, vol. 907, part B, pp. 11241129,$2007 ; 10^{\text {th }}$ ESAFORM Conference on Material Forming, Zaragoza, Spain, April 18-20, 2007.

[6] J. Vattulainen, E. Hämäläinen, R. Hernberg, P. Vuoristo, and T. Mäntylä. Novel Method for InFlight Particle Temperature and Velocity Measurement in Plasma Spraying Using a Single CCD Camera. J. Therm. Spray Technol. 10(1):94104, 2001.

[7] H. V. Atkinson, A. R. A. McLelland, W. M. Rainforth. Interfacial reactions during thixoforging of aluminium/SiC metal matrix composites. In: I. Verpoest, F. R. Jones (eds.): Interfacial phenomena in composite materials ' 91 : proceedings of the 2. international conference, pp. 227-230, Leuven, Belgium, September 17-19, 1991. Oxford : Butterworth-Heinemann, 1991.

[8] European Industrial Standard EN 10002-1 : 200112. Metallic materials - Tensile testing - Part 1 : Method of testing at ambient temperature.

[9] European Industrial Standard EN 658-3 : 2002-11. Advanced technical ceramics - Mechanical properties at room temperature - Part 3: Determination of flexural strength. 